\title{
JUSTIFICATION OF DIAZOLINE PERMISSIBLE LEVELS IN OCCUPATIONAL AIR IN CHEMICAL AND PHARMACEUTICAL INDUSTRIES
}

Danylo Halytsky Lviv National Medical University. Ministry of Health of Ukraine, 79010 Lviv, Ukraine

The toxicological assessment of diazoline, the first- generation antihistaminic preparation, was carried out together with justification of the hygiene standard for permissible content ( (Tentative Safe Exposure LevelTSEL) of occupational air in production premises. It was found out that according to acute oral toxicity criterion, Diazoline refers to low hazardous substances. In the clinical picture of acute and sub-chronic intoxication, CNS involvement prevails. Diazolin has a weak local irritant effect in case of contact with mucous membranes, shows a strong cumulative activity. In case of intracutaneous sensitization, it influences indicators of the cellular and humoral component of innate and acquired immunity. TSEL of diazoline in occupational air is $1.0 \mathrm{mg} / \mathrm{m}^{3}$.

Keywords: diazoline, toxicological assessment, hygienic standard, occupational air.

Переработанный материал поступил в редакцию 25.01.2016 г.

\section{ТОКСИКОЛОГИЧЕСКАЯ ОЦЕНКА БЕЗОПАСНОСТИ ЛИОФИЛИ- ЗАТОВ ДЛЯ ПРИГОТОВЛЕНИЯ РАДИОФАРМАЦЕВТИЧЕСКОГО ПРЕПАРАТА 68GA-ЦИТРАТ В ЭКСПЕРИМЕНТЕ НА ГРЫЗУНАХ}

А.С. Лунёв ${ }^{1,2}$, К.А. Петросова М.В. Жукова ${ }^{1}$, К.Э. Терновская О.Е. Клементьева ${ }^{1}$, Н.П. Льєенко

${ }^{1}$ ФГБУ ГНЦ Федеральный медицинский биофизический центр им. А.И. Бурназяна ФМБА России, 123098, г. Москва, Российская Федерация ${ }^{2}$ ФББОУ ВО Московская государственная академия ветеринарной медицины и биотехнологии -МВА им. К.И. Скрябина, 109472, г. Москва, Российская Федерация

( сследовано действие лиофилизатов «Цигалин» и «Фероцит» (ООО «ДИАМЕД») для приготовления радиофармацевтического препарата 68Ga-цитрат на организм лабораторных животных (крысы, мыши) с точки зрения токсичности. В ходе эксперимента установлена хорошая переносимость, отсутствие выраженных симптомов интоксикации, аллергизирующего действия и гибели животных в рекомендуемой для клинического применения дозе. «Цигалин» не оказывал токсического эффекта, влияющего на статистически значимые изменения основных гематологических и биохимических показателей крови. Подобные изменения для «Фероцита» в кратных дозах носили функционально-обратимый характер. Полученные результаты позволяют характеризовать лиофилизаты для приготовления 68Ga-цитрата как безопасные для дальнейшего клинического применения в радионуклидной диагностике для визуализации воспалительных процессов методом позитронной эмиссионной томографии.

Ключевые слова: Цигалин, Фероцит, 68Gа-циитрат, токсичность острая, хроническал, аллергизирующее действие, безопасность.

Лунёв Александр Сергеевич (Lunev Alexander Sergeevich), инженер отдела радиационных технологий в медицине ФГБУ ГНЦ ФМБЦ, 123098, аспирант кафедры радиобиологи и вирусологии ФГБОУ ВО МГАВМиБ - бывш. МВА,109472, г. Москва, I5h33@rambler.ru

Петросова Кристина Андреевна (Petrosova Kristina Andreevna), инженер отдела радиационных технологий в медицине ФГБУ ГНЦ ФМБЦ, 123098, г.

Москва, cwg747@rambler.ru

Жукова Мария Валерьевна (Zhukova Mariya Valeryevna), инженер отдела радиационных технологий в медицине ФГБУ гнц ФМБЦ, 123098, г. Москва, 9053522@mail.ru

Терновская Кристина Эдуардовна (Ternovskaya Kristina Eduardovna), инженер отдела радиационных технологий в медицине ФГБУ ГНЦ ФМБЦ, 123098

г. Москва, violet mak@mail.ru

Клементьева Ольга Евгеньевна (Klementyeva Olga Evgenyevna), кандидат биологических наук, заведующая лабораторией доклинических и клинических исследований радиофармацевтических препаратов отдела радиационных технологий в медицине ФГБУ ГНЦ ФМБЦ, 123098, г. Москва, klementyеva.olga@ gmail.com

Лысенко Николай Петрович (Lysenko Nikolay Petrovich), доктор биологических наук, заведующий кафедрой радиобиологии и вирусологии ФГБОУ ВПО

МГАВМиБ - бывш. МВА, 109472, г. Москва, nsvjn@mail.ru 
Введение. В настоящее время активно проводятся экспериментальные исследования новых радиофармацевтических препаратов (РФП), при этом их успешное внедрение в клиническую практику предполагает не только наличие доказанной высокой степени эффективности, но и безопасности применения еще на этапе доклинических испытаний.

68Ga-цитрат («Цигалин, 68Ga», OOO «ДИАМЕД», основное вещество в лиофилизате: натрия цитрат) с предварительным введением цитрата трехвалентного железа («Фероцит», ООО «ДИАМЕД») - инновационный РФП для внутривенного введения на основе радионуклида галлия-68 для неспецифической визуализации, идентификации и локализации очагов воспаления различной природы и локализации методом позитронной эмиссионной томографии (ПЭТ) [1]. «Фероцит» предназначен для ПЭТ-исследований с РФП на основе галлия-68, обладающих повышенным сродством к трансферрину крови (в частности, «Цигалин, 68Ga»), в качестве дополнительного блокирующего агента, позволяющего повысить контрастность получаемого ПЭТ-изображения. Уникальность 68Ga-цитрата состоит в простоте его приготовления непосредственно перед введением пациенту в ПЭТ-центре, логистически независимым от циклотрона и его дорогостоящей эксплуатации, так как изотоп галлия $68 \mathrm{Ga}$ является генераторным радионуклидом (генератор 68Ge/68Ga, 3АО «Циклотрон», Обнинск) [2].

Целью исследования безопасности применения «Цигалина» и «Фероцита» является выявление и оценка выраженности токсических эффектов, возникающих при взаимодействии лиофилизатов с организмом лабораторных животных. Важным отличием РФП является наличие радиоактивной метки, что предполагает токсикологическую оценку безопасности не только нерадиоактивных компонентов препарата, но и оценку токсических побочных эффектов от прямого действия ионизирующего излучения - оценку радиационной безопасности. Дополнительные дозиметрические исследования по расчету поглощенных доз и лучевых нагрузок, формируемых 68Ga-цитратом в организме, подтвердили его радиационную безопасность [3].

Объем доклинических исследований безопасности определен согласно МУ 2.6.1.046-2013 «Доклинические исследования радиофармацевтических препаратов для позитронно-эмиссионной томографии», утв. 4.07.2013 г. ФМБА России [4], и Руководству по проведению доклинических исследований лекарственных средств [5].

Материалы и методы исследования. Объектами исследования являлись лиофилизаты для приготовления растворов для внутривенного введения «Цигалин» и «Фероцит». Материалами исследования (тест-системами) являлись мыши линии BALB/c (самки и самцы) массой 21,4 41,7 г (140 шт.) и крысы (самцы и самки) линии Sprague

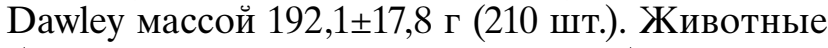
были получены из питомника лабораторных животных «Пущино» ФИБХ РАН. Дизайн исследования безопасности лиофилизатов представлен в таблице 1. Экспериментальные животные содержались в требуемых условиях при естественном световом режиме, на стандартной диете, свободном доступе к воде и пище. Животные были включены в эксперименты после 14-ти дневного карантина. Все манипуляции с животными, связанные с проведением экспериментальных работ и умерщвлением, проводились в соответствии с правилами проведения работ, методическими рекомендациями и правилами, принятыми Европейской конвенцией по защите позвоночных животных, используемых для экспериментальных и иных научных целей $[6,7,8]$.

\section{Расчет вводимых доз растворов лиофилизатов}

Расчет вводимых животным эквивалентных доз (ЭД) для оценки безопасности проводили с учетом коэффициентов пересчета человек/экспериментальное животное [5]. За предполагаемую однократную дозу введения для человека принимали содержание основного вещества в одном флаконе лиофилизата для приготовления РФП, установленное в период поисковых исследований по его составу.

\section{Исследование острой токсичности лиофи-} лизатов

Исследование проводили на мышах линии

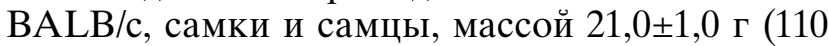
шт.: 50 шт. для Цигалина, 60 шт. для Фероцита). В целях исследования животных распределяли на контрольную и экспериментальные группы с расчетом увеличения вводимых доз, эквивалентных предполагаемой однократной для человека (ЭД), по 5 особей в группе для каждого пола, согласно дизайну исследований (табл. 1).

Объем вводимого раствора лиофилизата составил 0,1 мл. Животным контрольной группы вводили 0,1 мл 0,9\% раствор хлорида натрия. Критериями оценки острой токсичности являлись выживаемость и смертность (расчет $\mathrm{LD}_{50}$ с использованием метода логит-регрессии), внешний вид и поведение, реакция на внешние раздражители, болевая реакция, потребление корма и воды, количество и консистенция фекальных масс, частота мочеиспускания и цвет мочи. Наблюдение за тест-системами осуществляли на протяжении 14 календарных дней. По окончании наблюдения всех выживших животных выводили из эксперимента путем декапитации (эвтаназия не соответствует МТ) и проводили некропсию с последующим вычислением 
абсолютной и относительной массы органов и их стандартных отклонений.

Исследование хронической токсичности лиофилизатов

Исследование проводили на крысах линии Sprague Dawley массой тела 192,1+17,8 г (210 шт.: по 105 шт. для каждого лиофилизата). Методом случайной выборки с учетом массы тела и пола в качестве определяющего показателя были сформированы контрольная и экспериментальные группы, согласно дизайну исследований (табл. 1).
Объем вводимого внутривенно раствора лиофилизата составил 0,2 мл. Животным контрольной группы вводили 0,2 мл $0,9 \%$ раствор хлорида натрия. Критериями оценки хронической токсичности являлись выживаемость, визуальная оценка общего состояния исследуемых животных, результаты общего клинического анализа крови, биохимического анализа крови и патоморфологическое исследование. Общий клинический анализ крови проводили на автоматическом гематологическом ветеринарном

Таблица 1

Дизайн исследования безопасности радиофармацевтического препарата 68Ga-цитрат

\begin{tabular}{|c|c|c|c|c|c|c|c|c|c|}
\hline \multirow{4}{*}{\multicolumn{2}{|c|}{$\begin{array}{c}\text { Вводимые дозировки } \\
\text { растворов лиофилизатов }\end{array}$}} & \multicolumn{8}{|c|}{ Лабораторные животные для исследования безопасности } \\
\hline & & \multicolumn{5}{|c|}{ мыши линии BALB/c, шт. } & \multicolumn{3}{|c|}{ крысы линии Sprague Dawley, шт. } \\
\hline & & \multirow{2}{*}{$\begin{array}{l}\text { Доза, } \\
\text { мг/кг }\end{array}$} & \multicolumn{2}{|c|}{ Острая токсичность } & \multicolumn{2}{|c|}{$\begin{array}{l}\text { Аллергезирующее } \\
\text { действие }\end{array}$} & \multirow[t]{2}{*}{$\begin{array}{l}\text { Доза, } \\
\text { мг/кг }\end{array}$} & \multicolumn{2}{|c|}{$\begin{array}{l}\text { Субхроническая } \\
\text { токсичность** }\end{array}$} \\
\hline & & & $\lambda^{\lambda}$ & q & $0^{\lambda}$ & q & & o & q \\
\hline \multicolumn{2}{|c|}{ Контроль } & - & 5 & 5 & 5 & 5 & - & 5 & 5 \\
\hline \multirow{2}{*}{ ЭД } & Ц* & 8,0 & 5 & 5 & 5 & 5 & 3,7 & 25 & 25 \\
\hline & $\Phi^{*}$ & 1,8 & 5 & 5 & 5 & 5 & 0,8 & 25 & 25 \\
\hline \multirow{2}{*}{ ЭДх5 } & ц & - & - & - & - & - & - & - & - \\
\hline & $\Phi$ & 9,1 & 5 & 5 & - & - & - & - & - \\
\hline \multirow{2}{*}{ ЭДх10 } & ц & 80,4 & 5 & 5 & - & - & 37,1 & 25 & 25 \\
\hline & $\Phi$ & 18,2 & 5 & 5 & - & - & 8,4 & 25 & 25 \\
\hline \multirow{2}{*}{ ЭД $\times 20$} & ц & 160,8 & 5 & 5 & - & - & - & - & - \\
\hline & $\Phi$ & 36,4 & 5 & 5 & - & - & - & - & - \\
\hline \multirow{2}{*}{ ЭД $\times 40$} & Ц & - & - & - & - & - & - & - & - \\
\hline & $\Phi$ & 72,8 & 5 & 5 & - & - & - & - & - \\
\hline \multirow{2}{*}{ ЭД $\times 50$} & ц & 402,1 & 5 & 5 & - & - & - & - & - \\
\hline & $\Phi$ & 91,0 & 5 & 5 & - & - & - & - & - \\
\hline \multirow{2}{*}{\multicolumn{2}{|c|}{ Всего животных, шт. }} & \multicolumn{3}{|c|}{110} & \multicolumn{2}{|c|}{30} & & \multirow{2}{*}{\multicolumn{2}{|c|}{210}} \\
\hline & & \multicolumn{5}{|c|}{140} & & & \\
\hline
\end{tabular}

Примечание: * Ц - Цигалин, Ф - Фероцит

** Каждая группа по 25 крыс разделена на 5 временных точек $(0,5,10,15,21$ сутки) по 5 крыс на точку 
анализаторе Exigo 17 (Boule Medical, Швеция) с использованием пластиковых микропипеток на 30 мкл с антикоагулянтом ЭДТА-К2. Биохимический анализ крови (содержание общего белка, железа, трансаминаз, ЩФ, ЛДГ) проводили на полуавтоматическом биохимическом анализаторе StatFax 4500 (США) с использованием стандартных наборов реагентов UTS (Юнимед, Россия) и пробирок с активатором свертывания (Sarstedt, Германия).

Исследование аллергизирующего действия лиофилизатов

Аллергенность лиофилизатов оценивали по реакции гиперчувствительности замедленного типа (ГЗТ) [9]. Исследования проводили на мышах линии BALB/c (самцы и самки) массой тела 20,08 $\pm 1,2$ г (30 шт.). Методом случайной выборки с учётом массы тела и пола в качестве определяющего показателя были сформированы контрольная и экспериментальные группы, согласно дизайну исследований (табл. 1).

Мышей сенсибилизировали однократным внутрикожным введением в основание хвоста 0,2 мл эмульсии компонентов флаконов с лиофилизатами в полном адъюванте Фрейнда (ПАФ) в соотношении 1:1. Контрольных животных сенсибилизировали эмульсией ПАФ с раствором Хенкса (1:1). Через 5 суток всем группам мышей в подушечку задней лапы вводили 0,1 мл раствора лиофилизата в растворе Хенкса. Контрольной группе животных вводили в подушечку задней лапы 0,1 мл физиологического раствора. Через 24 часа после тестирования измеряли величину отека с помощью инженерного микрометра MK-0-25. Разница в толщине обеих лапок характеризует степень развития отека, по которой оценивали интенсивность реакции ГЗТ.

\section{Статистическая обработка результатов}

Все полученные данные обработаны методами математической статистики с применением пакета Microsoft Excel. При статистической обработке результатов исследования определяли показатели средних арифметических значений (M), стандартных ошибок с учетом отклонения значений выборки от средних арифметических $( \pm \mathrm{m})$. Нормальность распределения проверяли с использованием теста Колмогорова-Смирнова. При условии соответствия распределения нормальности достоверность полученных различий сопоставляемых величин оценивали с использованием t-критерия Стьюдента. При несоответствии нормальности распределения достоверность различий оценивали с использованием $\mathrm{U}$-критерия Манна - Уитни. Частоты признаков сравнивались с использованием критерия $\chi^{2}$. Различия считали достоверными при $\mathrm{p}<0,05$.

Результаты и обсуждение.

Острая токсичность
На протяжении всего исследования летальность отсутствовала во всех группах мышей с введенным раствором Цигалина. Таким образом, определить значение ЛД 50 не представилось возможным. Введение не вызвало отрицательного воздействия на поведение и внешний вид. В течение 14 суток наблюдения животные выглядели здоровыми, без выраженных признаков интоксикации. Двигательная активность, потребление пищи, состояние волосяного и кожного покрова, реакция на различные раздражители соответствовали норме. Количество и консистенция фекальных масс, частота мочеиспускания и цвет мочи соответствовали физиологической норме. Шерстный покров густой, белого цвета. По внешнему виду животные между группами не отличались. На протяжении эксперимента было произведено три контрольных взвешивания. Масса тела достоверно не отличалась между группами и имела положительную динамику.

Иную картину наблюдали для Фероцита: на протяжении всего исследования летальность отсутствовала только в группах ЭД и ЭДх5; в остальных группах (ЭДх10, ЭДх20, ЭДх40) общая летальность (по самцам и самкам) составила $30 \%, 60 \%$ и $80 \%$, соответственно. В группе ЭДх50 летальность самцов и самок составила $100 \%$. Значение полулетальной дозы $\mathrm{LD}_{50}$ составило 60 мг/кг массы мыши при внутривенном введении, что примерно равно 17-кратной дозе ЭД.

Введение раствора Фероцита в дозах, не превышающих эквивалентную предполагаемой для клинического применения в 5 раз, не вызывало отрицательного воздействия на поведение и внешний вид. В течение 14 суток наблюдения животные выглядели здоровыми, без выраженных признаков интоксикации и достоверных различий с контролем в положительной динамике набора массы. У павших мышей в группах ЭДх10, ЭДх20, ЭДх40 до гибели отмечали меньшую двигательную активность и большую потребность в потреблении воды. Внешний вид мышей не отличался от контроля. Среди выживших мышей не отмечали случаи сколько-нибудь значимых признаков интоксикации и отличия от контроля.

При аутопсии различий между контрольной и опытными группами для Цигалина и Фероцита (всех выживших животных) выявлено не было. Расположение внутренних органов соответствует норме. Просвет трахеи и бронхов свободен, слизистая их чистая, влажная, блестящая. Сердце правильной формы, не увеличено, миокард упругой консистенции, влажный, блестящий, рисунок волокон выражен хорошо. Большие сосуды, лежащие в области перикар- 


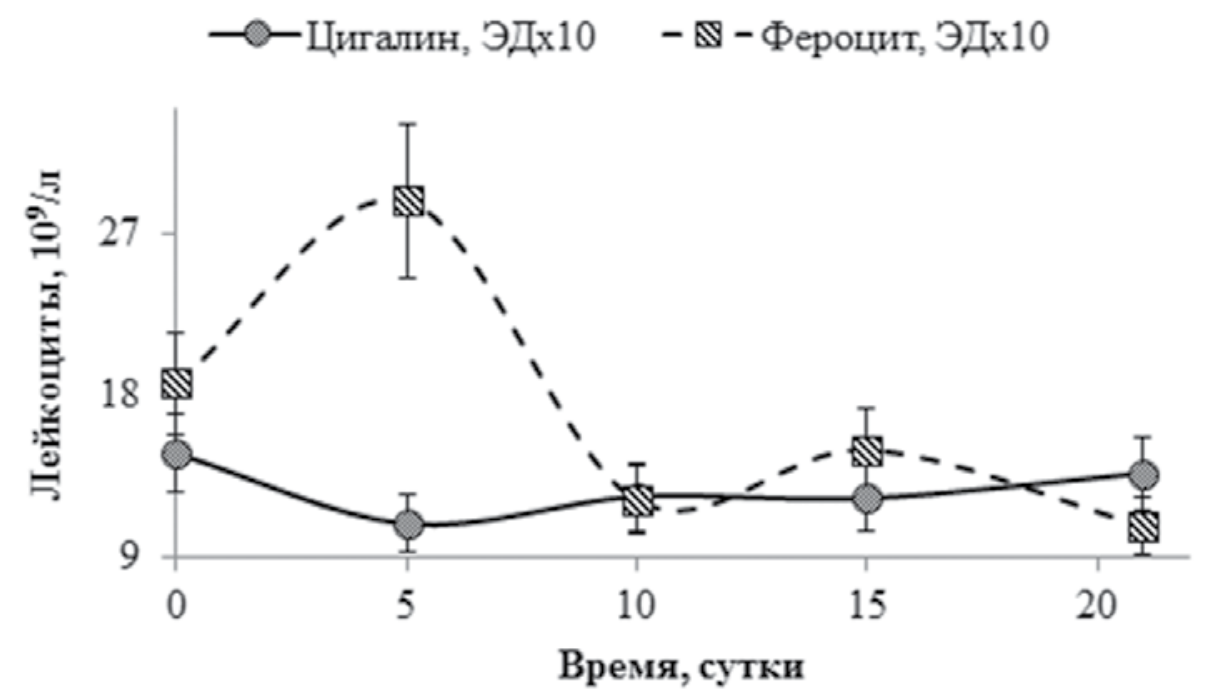

Рис. 1. Динамика изменения значений концентрации лейкоцитов в цельной крови крыс после введения десятикратных доз Цигалина и Фероцита

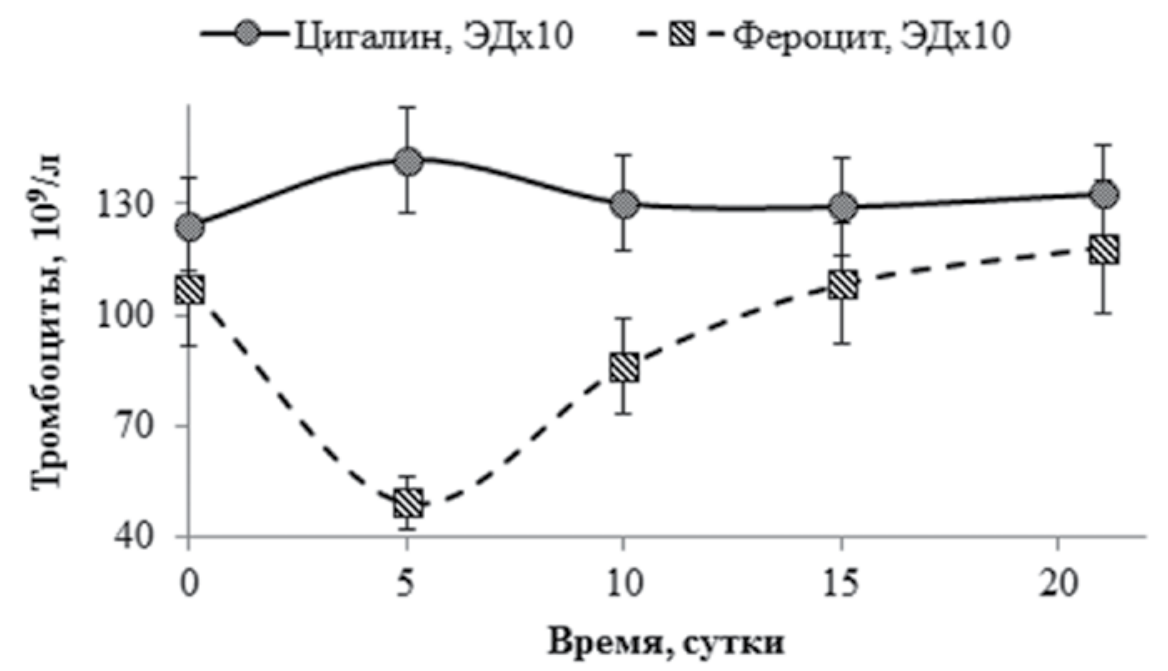

Рис. 2. Динамика изменения значений концентрации тромбоцитов в цельной крови крыс после введения десятикратных доз Цигалина и Фероцита

да, хорошо выражены. В полости сердечной сумки находится несколько капель прозрачной соломенно-желтого цвета жидкости. Легкие умеренно спавшиеся, имеют гладкую мягкую поверхность. Селезенка не увеличена, вытянутой формы, поверхность гладкая, консистенция плотная, на разрезе: пульпа не соскабливается, фолликулы и трабекулы имеют вид серых точек и полосок. Печень правильной формы, не увеличена, плотной консистенции, гладкая и блестящая. Почки правильной бобовидной формы, фиброзная капсула легко отделяется. На разрезе хорошо видна граница коркового и мозгового слоев. Желудок и кишечник без вздутия, без спаек. Тимус без кровоизлияний. Щитовидная железа плотная с симметричными долями. Оболочки головного мозга умеренного кровенаполнения, влажные, блестящие. Мозговое вещество имеет симметричный рисунок на разрезе.

У павших животных после внутривенного введения высоких доз Фероцита отмечали незначи- 
घЦигалин, ЭД口Фероцит, ЭД $\mathbf{ш и г а л и н , ~ Э Д х 1 0 ~} ₫$ Фероцит, ЭДх10

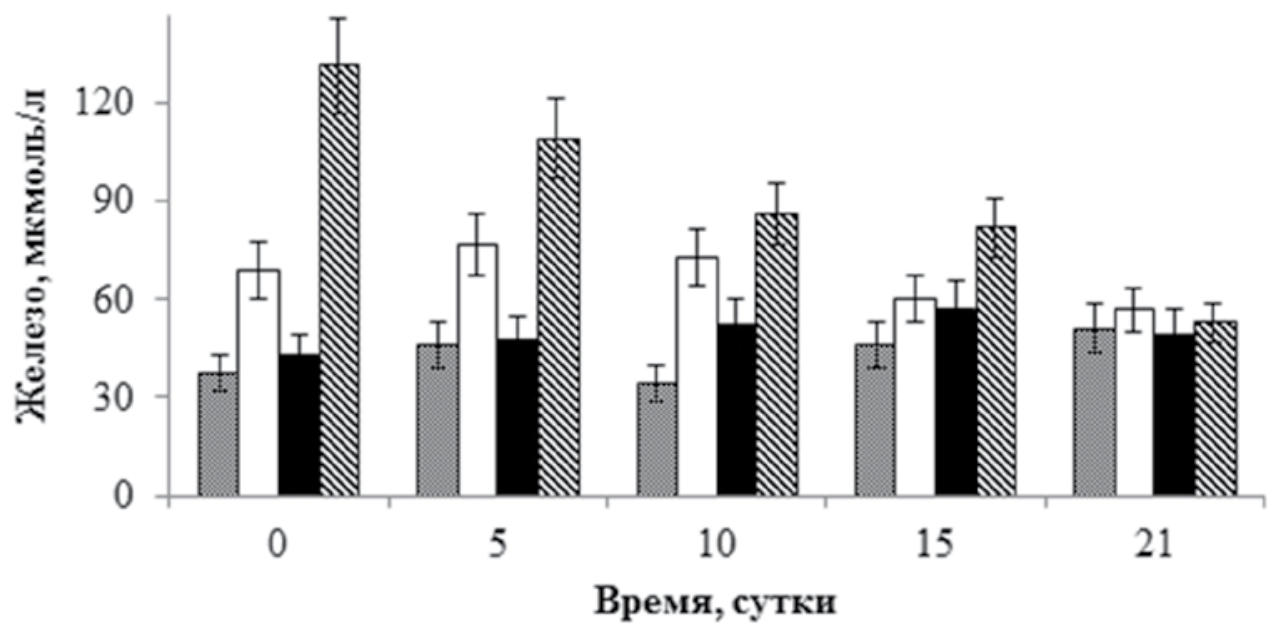

Рис. 3. Динамика изменения значений железа в плазме крови крыс после введения различных доз Цигалина и Фероцита

घЦигалин, ЭД РФероцит, ЭД घ Цигалин, ЭДх10 \& Фероцит, ЭДх10

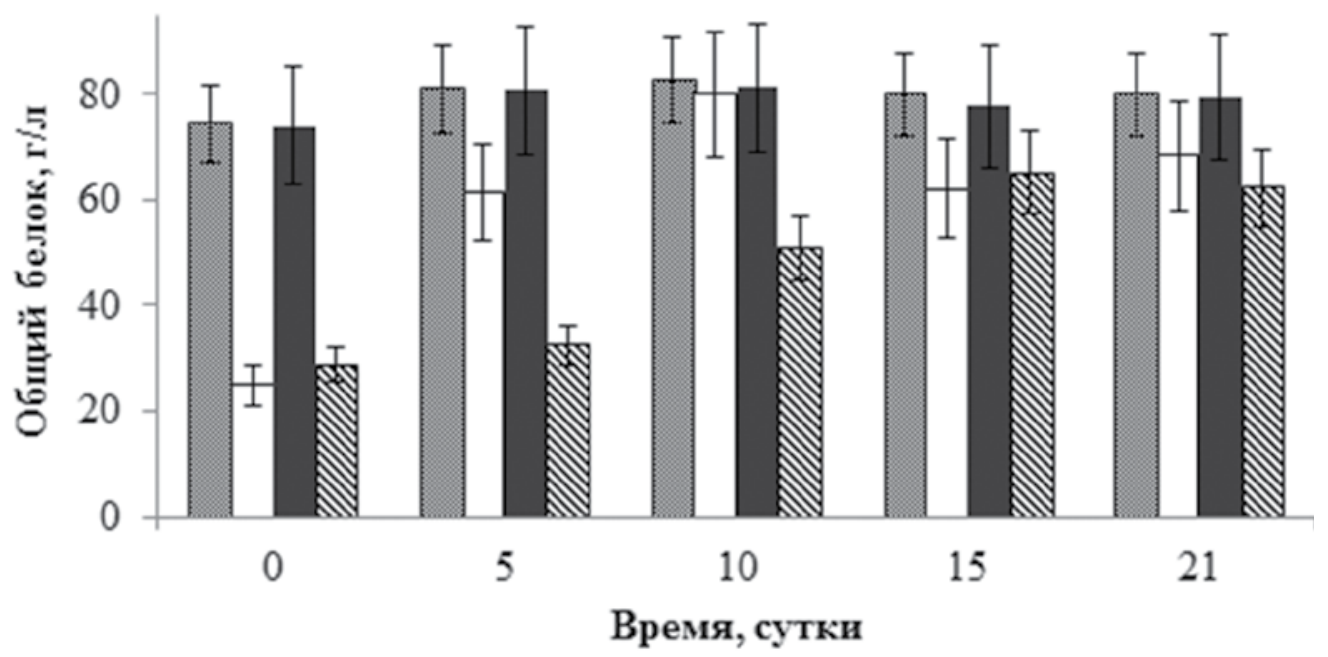

Рис. 4. Динамика изменения значений общего белка в плазме крови крыс после введения различных доз Цигалина и Фероцита

тельное потемнение печени в сравнении с контролем.

\section{Хроническая токсичность}

Общее состояние животных на протяжении всего эксперимента было в норме, отклонений не обнаружено, павшие животные отсутствовали. По результатам контрольных взвешиваний, во всех группах животных отмечена положительная динамика. Результаты по общему клиническому анализу крови (ОКА) представлены в таблице 2. Следует отметить отсутствие статистически достоверной разницы по половому признаку между значениями показателей крови. Более того, введение крысам раствора Цигалина в десятикратной дозе не приводило к значимым изменениям показателей крови. Напротив, введение Фероцита в 10-кратной дозе привело на 5 сутки к резкому повышению лейкоцитов и понижению тромбоцитов, однако скачки имели функционально-обратимый характер - к 10-15 суткам между значениями для разных групп лиофилизатов и контролем не было статистически достоверной разницы. (рис. 1, 2). 
Таблица 2

Сравнение полученных результатов ОКА крови исследуемых крыс (Ц - Цигалин, Ф - Фероцит)

\begin{tabular}{|c|c|c|c|c|c|c|c|c|}
\hline \multirow{2}{*}{ 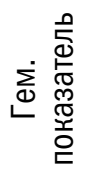 } & \multirow{2}{*}{ 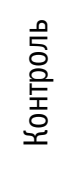 } & \multirow{2}{*}{\multicolumn{2}{|c|}{$\begin{array}{c}\text { Доза } \\
0\end{array}$}} & \multicolumn{5}{|c|}{ Временные точки, сутки } \\
\hline & & & & 5 & 10 & 15 & 21 & \\
\hline \multirow{4}{*}{ 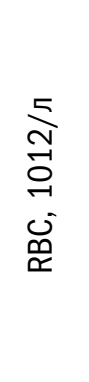 } & \multirow{4}{*}{$\begin{array}{l}\hat{0} \\
0 \\
+1 \\
0 \\
\omega^{\prime}\end{array}$} & \multirow{2}{*}{ శ్రా } & Ц & $6,5 \pm 0,9$ & $7,1 \pm 0,5$ & $7,2 \pm 0,1$ & $8,2 \pm 0,9$ & $7,0 \pm 0,8$ \\
\hline & & & $\Phi$ & $7,1 \pm 0,7$ & $6,1 \pm 1,4$ & $8,7 \pm 1,7$ & $7,9 \pm 2,1$ & $8,4 \pm 0,6$ \\
\hline & & \multirow{2}{*}{$\begin{array}{l}\text { 엄 } \\
\text { à } \\
\text { के }\end{array}$} & Ц & $6,9 \pm 1,0$ & $7,2 \pm 0,9$ & $6,5 \pm 0,8$ & $7,2 \pm 0,8$ & $7,6 \pm 1,0$ \\
\hline & & & $\Phi$ & $\begin{array}{l}7,8 \pm 0,3 \\
*\end{array}$ & $\begin{array}{c}8,6 \pm 0,2 \\
* / * *\end{array}$ & $\begin{array}{c}9,3 \pm 0,4 \\
* / * *\end{array}$ & $\begin{array}{c}9,3 \pm 0,3 \\
* / * *\end{array}$ & $8,1 \pm 1,7$ \\
\hline \multirow{4}{*}{$\begin{array}{l}\circ \\
\text { ó } \\
\text { í }\end{array}$} & \multirow{4}{*}{ 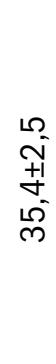 } & \multirow{2}{*}{ శ్రి } & ц & $33,6 \pm 4,0$ & $36,3 \pm 1,6$ & $37,5 \pm 2,0$ & $41,3 \pm 4,9$ & $35,5 \pm 2,9$ \\
\hline & & & $\Phi$ & $28,9 \pm 4,3$ & $26,7 \pm 6,3$ & $38,7 \pm 7,3$ & $34,9 \pm 3,1$ & $34,4 \pm 0,4$ \\
\hline & & \multirow{2}{*}{ 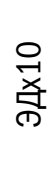 } & ц & $35,9 \pm 4,0$ & $37,4 \pm 2,6$ & $35,0 \pm 0,8$ & $37,2 \pm 2,0$ & $37,3 \pm 1,2$ \\
\hline & & & $\Phi$ & $37,4 \pm 1,7$ & $37,4 \pm 1,0$ & $41,5 \pm 1,4 * / * *$ & $\begin{array}{c}41,0 \pm 1,7 \\
* / * *\end{array}$ & $41,0 \pm 0,7$ \\
\hline \multirow{4}{*}{ 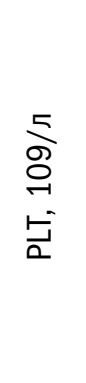 } & \multirow{4}{*}{ 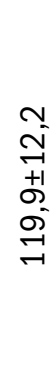 } & \multirow{2}{*}{ శ్రి } & Ц & $119,3 \pm 14,0$ & $110,0 \pm 18,5$ & $138,3 \pm 3,6$ & $141,0 \pm 3,6$ & $143,0 \pm 10,6$ \\
\hline & & & $\Phi$ & $125,1 \pm 7,3$ & $133,7 \pm 11,6$ & $110,3 \pm 18,2$ & $115,3 \pm 16,2$ & $128,3 \pm 5,8$ \\
\hline & & \multirow{2}{*}{$\begin{array}{l}\stackrel{ }{x} \\
\text { 爻 } \\
\text { के }\end{array}$} & Ц & $124,3 \pm 6,8$ & $142,0 \pm 14,8$ & $130,3 \pm 6,1$ & $129,3 \pm 2,1$ & $132,7 \pm 5,1$ \\
\hline & & & $\Phi$ & $107,5 \pm 7,7$ & $\begin{array}{c}49,3 \pm 5,6 \\
* / * *\end{array}$ & $\begin{array}{l}86,0 \pm 12,0 \\
* / * *\end{array}$ & $108,3 \pm 5,6$ & $118,3 \pm 12,9$ \\
\hline \multirow{4}{*}{$\begin{array}{l}5 \\
\frac{5}{8} \\
0 \\
0 \\
0 \\
0 \\
0\end{array}$} & \multirow{4}{*}{$\begin{array}{l}\infty \\
\underset{+}{+} \\
+ \\
+ \\
+ \\
+\end{array}$} & \multirow{2}{*}{ శ్ } & Ц & $15,7 \pm 0,9$ & $13,6 \pm 5,1$ & $14,8 \pm 2,4$ & $18,3 \pm 1,1$ & $16,9 \pm 2,0$ \\
\hline & & & $\Phi$ & $14,7 \pm 4,0$ & $13,9 \pm 2,6$ & $10,9 \pm 1,7$ & $16,4 \pm 6,8$ & $13,9 \pm 4,9$ \\
\hline & & \multirow{2}{*}{$\begin{array}{l}\text { 엄 } \\
\text { 爻 } \\
\text { के }\end{array}$} & Ц & $14,8 \pm 3,5$ & $10,9 \pm 2,6$ & $12,4 \pm 1,1$ & $12,3 \pm 2,1$ & $13,7 \pm 0,4$ \\
\hline & & & $\Phi$ & $18,7 \pm 2,5$ & $\begin{array}{c}28,8 \pm 3,7 \\
* / * *\end{array}$ & $12,2 \pm 2,2$ & $15,0 \pm 1,7$ & $10,8 \pm 2,2$ \\
\hline \multirow{4}{*}{$\begin{array}{l}5 \\
5 \\
90 \\
\text { 오 }\end{array}$} & \multirow{4}{*}{ 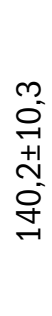 } & \multirow{2}{*}{ శ్ } & Ц & $136,7 \pm 8,5$ & $142,3 \pm 1,5$ & $138,0 \pm 7,2$ & $153,7 \pm 17,4$ & $142,3 \pm 8,1$ \\
\hline & & & $\Phi$ & $137,7 \pm 3,9$ & $112,3 \pm 23,1$ & $157,3 \pm 22,2$ & $135,3 \pm 35,6$ & $163,0 \pm 12,0$ \\
\hline & & \multirow{2}{*}{$\begin{array}{l}\stackrel{ }{x} \\
\text { 爻 } \\
\text { के }\end{array}$} & Ц & $134,0 \pm 15,1$ & $140,7 \pm 8,6$ & $131,3 \pm 2,5$ & $137,7 \pm 5,0$ & $155,0 \pm 11,0$ \\
\hline & & & $\Phi$ & $144,7 \pm 1,5$ & $146,0 \pm 3,3$ & $162,3 \pm 15,6$ & $159,0 \pm 16,7$ & $159,3 \pm 11,1$ \\
\hline
\end{tabular}

Примечание: * различие в сравнении с контролем значимо $(p<0,05)$

** различие в сравнении с группой ЭД значимо $(p<0,05)$ 
घЦигалин, ЭД口Фероцит, ЭД $Ц$ Цигалин, ЭДх10 \& Фероцит, ЭДх10

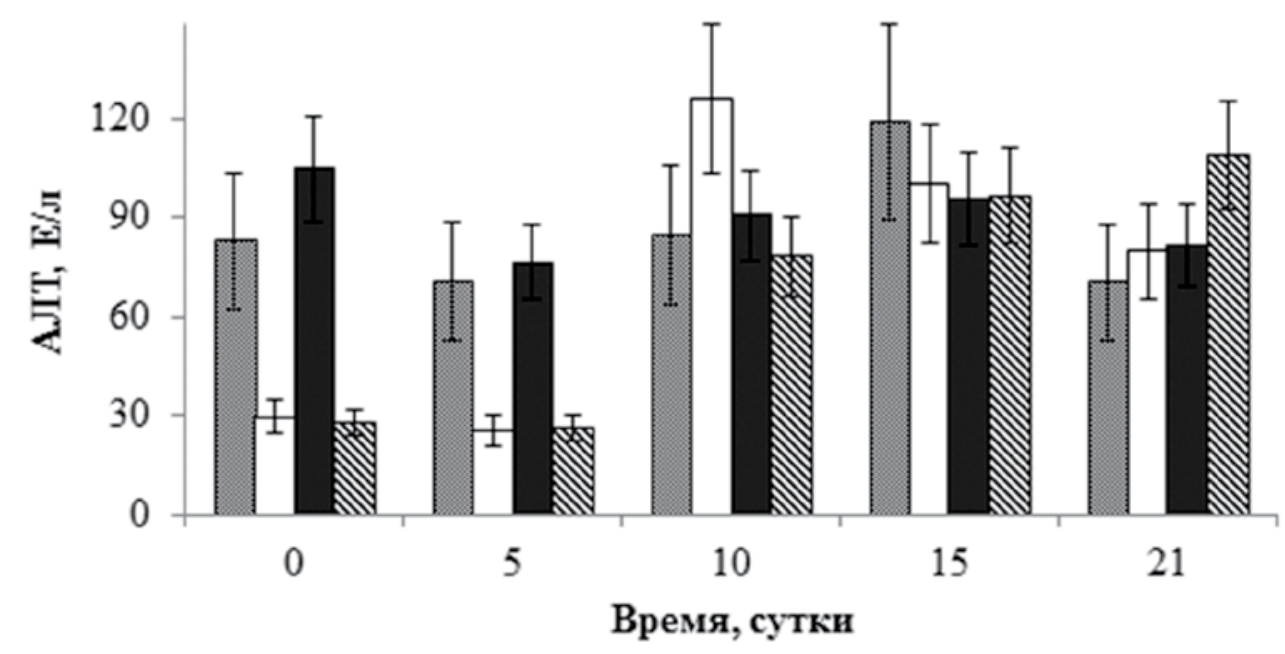

Рис. 5. Динамика изменения значений АЛТ в плазме крови крыс после введения различных доз Цигалина и Фероцита

口Цигалин, ЭД口Фероцит, ЭД $\mathbf{\square и г а л и н , ~ Э Д х 1 0 ~ \$ Ф е р о ц и т , ~ Э Д х 1 0 ~}$

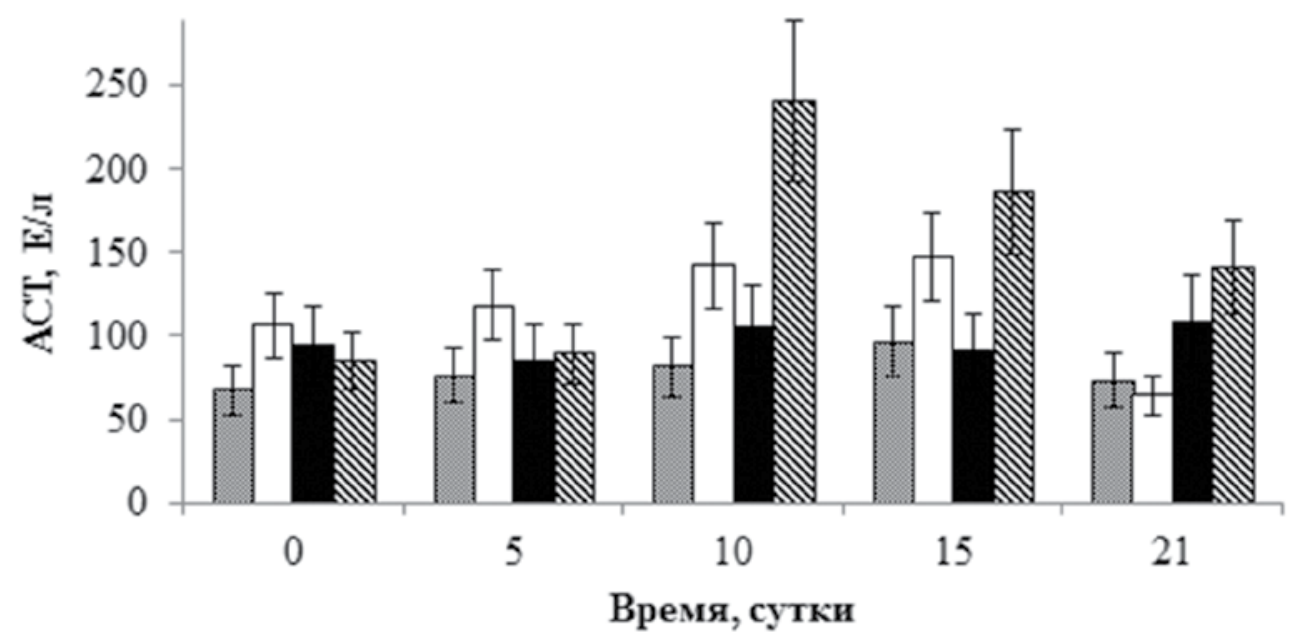

Pис. 6. Динамика изменения значений АСТ в плазме крови крыс после введения различных доз Цигалина и Фероцита

Результаты биохимического анализа плазмы крови позволили сделать вывод о высокой степени безопасности применения лиофилизата Цигалин. В исследуемых дозах раствор лиофилизата не приводил к статистически значимым изменениям показателей плазмы крови в сравнении с контрольными животными. Следует также указать на отсутствие статистически достоверной разницы между концентрациями различ- ных биохимических показателей крови у самцов и самок.

Напротив, резкое повышение концентрации железа в крови (рис. 3) после введения Фероцита в десятикратной дозе запускало механизмы утилизации лишнего количества железа из крови посредством соединения железа с транспортными белками и их аккумуляции в печени, что явилось причиной резкого снижения уровня общего белка в крови (рис. 4). Излишнее на- 
口Цигалин, ЭД口Фероцит, ЭД Шииалин, ЭДх10 \$ Фероцит, ЭДх10

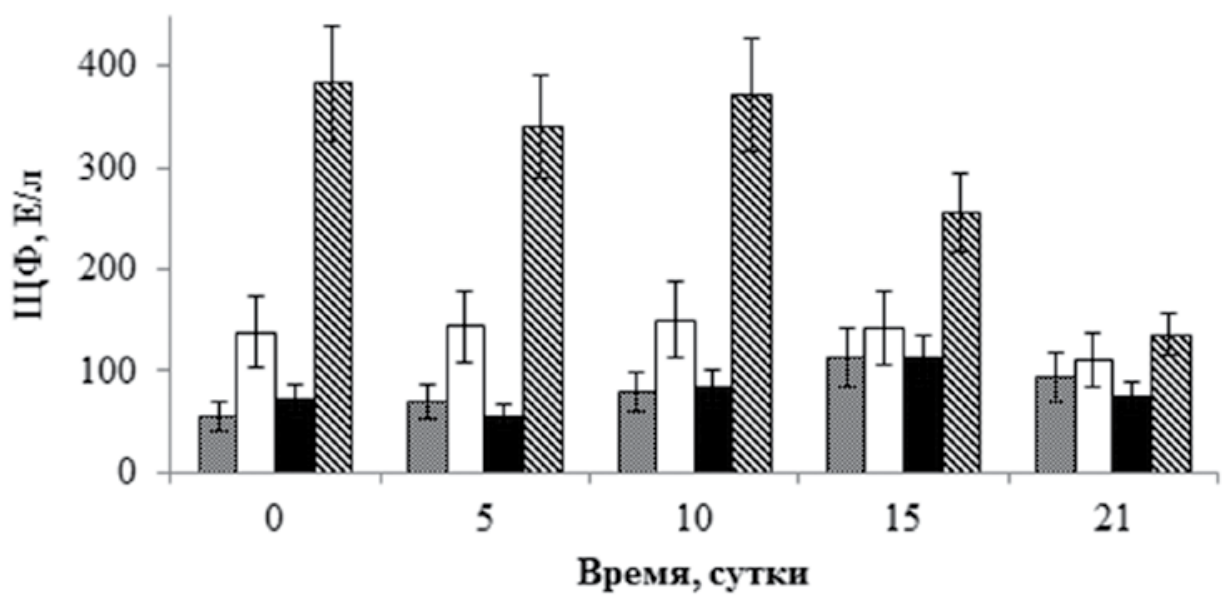

Рис. 7. Динамика изменения значений ЩФ в плазме крови крыс после введения различных доз Цигалина и Фероцита

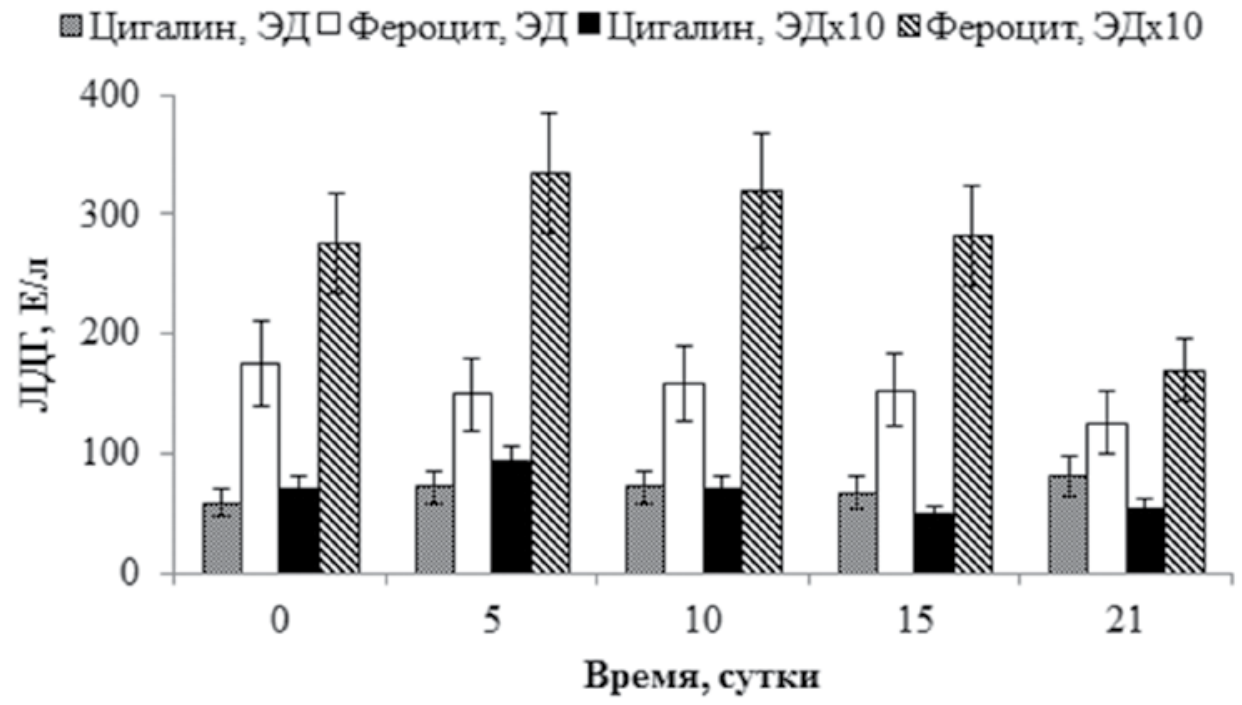

Рис. 8. Динамика изменения значений лдг в плазме крови крыс после введения различных доз Цигалина и Фероцита

копление железа в печени привело к увеличенной метаболической активности гепатоцитов, смещению равновесия между концентрациями трансаминаз (рис. 5,6) и резкому повышению уровня ЩФ (рис. 7) и ЛДГ (рис. 8).

Введение Фероцита крысам в десятикратной дозе приводило к симптомам токсического гепатита, однако носящего функционально-обратимый характер - к 15-20 суткам после введения не фиксировали статистически достоверной разницы между значениями в экспериментальных и контрольной группах.

При вскрытии у крыс во всех группах кожа была чистая, подкожно-жировой слой развит умеренно. Внутренние органы не увеличены, расположение правильное; гидроторакс отсутствует; слизистая трахеи и бронхов чистая, влажная, блестящая, просвет свободен.

\section{Аллергизирующие свойства}

После введения тест-препарата отмечено по- 
краснение на лапке, скорее всего, являющееся следствием укола. Разницы в толщине обеих лапок не выявлено, отечности не было.

Заключение. В экспериментах были получены и проанализированы данные о действии растворов лиофилизатов для приготовления радиофармацевтического препарата $68 \mathrm{Ga-цитрат}$ на организм грызунов (крысы, мыши) с точки зрения токсичности. В ходе эксперимента установили хорошую переносимость, полное отсутствие выраженных симптомов, аллергизирующего действия. Гибель животных отмечали лишь для высоких доз введения Фероцита. Ли- офилизаты в рекомендуемых для клинического применения дозах не оказывали токсического эффекта, влияющего на статистически значимые изменения основных гематологических и биохимических показателей крови. После введения десятикратной дозы Фероцита наблюдали симптомы, носящие функционально-обратимый характер. Полученные результаты позволяют характеризовать лиофилизаты как безопасные для дальнейшего клинического применения в радионуклидной диагностике для визуализации воспалительных процессов методом ПЭТ.

\section{СПИСОК ЛИТЕРАТУРЫ}

\author{
1. Nanni C., Errani C., Boriani L., et. \\ al. 68Ga-Citrate PET/CT for Evaluating \\ Patients with Infections of the Bone: \\ Preliminary Results. J. Nucl. Med. 2010; \\ 51: 1932-1936. \\ 2. Ларенков А.А., Брускин А.Б., Кодина \\ Г.Е. Способ получения активной фар- \\ мацевтической субстанции для синтеза \\ препаратов галлия-68. Патент РФ № RU \\ 2522892 С2 от 20.07.2014 г. \\ 3. Лунёв А.С., Клементьева O.Е.,
}

\section{REFERENCES:}

\author{
1. Nanni C., Errani C., Boriani L. et \\ al. 68Ga-Citrate PET/CT for Evaluating \\ Patients with Infections of the Bone: \\ Preliminary Results. J. Nucl. Med. 2010; \\ 51: 1932-1936. \\ 2. Larenkov A.A., Kodina G.E. \\ Bruskin A.B. Producing method of \\ active pharmaceutical substance for \\ the synthesis gallium-68-labelled \\ pharmaceutical. Patent RF, N 2522892; \\ 2014 (in Russian)
}

Кодина Г.Е. Расчетные исследования прогнозных значений поглощенных доз для оценки безопасности радиофармацевтического препарата 68Ga-цитрат. Медицинская радиология и радиационная безопасность. 2015; 60(4): 19-26. 4. Доклинические исследования радиофармацевтических препаратов для позитронно-эмиссионной томографии Методические указания 2.6.1.0462013, утв. 4.07.2013 ФМБА России.
M.; 2013.

5. Руководство по проведению доклинических исследований лекарственных средств. Часть первая. М.: Гриф и К; 2012.

6. ГОСТ 33044-2014 от 01.08.2015 Принципы надлежащей лабораторной практики. Межгос. Совет по стандар тизации, метрологии и сертификации М.; 2015.

7. Эвтаназия экспериментальных животных. Методические рекомендации. M.; 1985.

8. European Convention for the Protection Vertebrate Animals Use for Experimental and Other Scientific Purposes ETS N 123. March 18 1986. Strasbourg; 1986. 9. Любимов Б.И., Коваленко Л.П., Федосеева В.Н. и др. Оценка аллергизирующих свойств фармакологических веществ. Методические рекомендации №98/300. М.; 2000 .

\section{Lunev A.S., Klementyeva O.E., Kodina G.E. Computational research of prognosis values of absorbed doses for pre-clinical safety evaluation of radiopharmaceutical 68Ga-citrate. Meditsinskaya radiologiya i radiatsionnaya bezopasnost. 2015; 60(4): 19-26.(in Russian) \\ 4. Preclinical studying of radiopharmaceutical for positron emissio tomography. HOWTO 2.6.1.046-2013.} Moscow; 2013. (in Russian)
5. Guidance on preclinical studying of pharmaceutical. Part I. Moscow: Grif \& K; 2012.(in Russian)

6. State Standard 33044-2014 by 01.08.2015 Good Laboratory Practice. Interstate Council of standardization, metrology and certification. Moscow; 2015.(in Russian)

7. Euthanasia of experimental animals. Guidelines. Moscow; 1985.(in Russian) 8. European Convention for the Protection
Vertebrate Animals Use for Experimental and Other Scientific Purposes ETS N 123. March 18 1986. Strasbourg; 1986 9. Lyubimov B.I., Lovalenko L.P., Fedoseeva V.N. et al. The allergenic properties assessment of pharmaceutical. Guidelines No 98/300. Moscow; 2000. (in Russian)

\section{A.S. Lunev ${ }^{1,2}$, K.A. Petrosova ${ }^{1}$, M.V. Zhukova ${ }^{1}$, K.E. Ternovskaya ${ }^{1}$, O.E. Klementyeva ${ }^{1}$, N.P. Lysenko}

${ }^{1}$ A.I.Burnasyan Federal Medical Biophysical Center, 123098, Moscow, Russian Federation

${ }^{2}$ Moscow State Academy of Veterinary Medicine and Biotechnology, 109472, Moscow, Russian Federation

Toxicity effects of «Cigalin» and «Ferocit» lyophilizates used for formulation of the radiopharmaceutical preparation 68Ga-citrate were studied in animal organisms (rats, mice). Good tolerability, absence of pronounced intoxication symptoms, allergenic effects and animal deaths were noted in experiments using a recommended clinic dose of lyophilizates. «Cigalin» didn’t produce toxicity effects influencing on statistically significant changes in blood main hematological and biochemical parameters. Similar changes in case of «Ferocit» used in multiple doses were functionally reversible. The results permit to characterize 68Ga-citrate as safe for clinical applications in radionuclide diagnostics for PET imaging of inflammation and infection.

Keywords: Cigalin, Ferocit, 68Ga-citrate, acute toxicity, chronic toxicity, allergenic effect, safety. 